\title{
Morbidly Adherent Placenta: Its Management and Maternal and Perinatal Outcome
}

\author{
H. K. Chaudhari ${ }^{1,2} \cdot$ P. K. Shah ${ }^{1} \cdot$ Natasha D'Souza $^{1}$
}

Received: 23 April 2016/Accepted: 20 June 2016/Published online: 7 July 2016

(C) Federation of Obstetric \& Gynecological Societies of India 2016

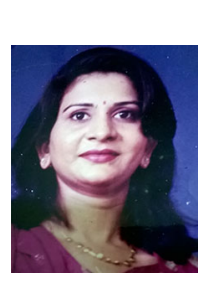

\begin{abstract}
About the Author
H. K. Chaudhari had completed her education at Seth G. S. Medical College and K. E. M. Hospital, Mumbai, a premier tertiary care institute in the country, and is currently working as Associate Professor in the same institute. Apart from keen interest in academics and research, she also has experience in emergency Obstetrics and endoscopy. She is a Co-Investigator in multiple research projects by the National Institute for Research in Reproductive Health (N.I.R.R.H.).
\end{abstract}

Dr. H. K. Chaudhari is an Associate Professor in Department of Obstetrics and Gynaecology at Seth G. S. Medical college and K.E.M. Hospital, Mumbai; Dr. P. K. Shah is a Professor in Department of Obstetrics and Gynaecology at Seth G. S. Medical College and K.E.M. Hospital, Mumbai; Dr. Natasha D'Souza is a Resident in Department of Obstetrics and Gynaecology at Seth G. S. Medical College and K.E.M. Hospital, Mumbai.

H. K. Chaudhari

hemangichaudharik@gmail.com

P. K. Shah

drpkshah2010@gmail.com

Natasha D'Souza

natdsouza.87@gmail.com

1 Department of Obstetrics and Gynaecology, Seth G. S. Medical College and K.E.M. Hospital, Mumbai, India

2 B/4, Highland Harmony, Opposite Panchasheel Joggers Park, Mahavir Nagar, Kandivali (W), Mumbai 400 069, India

\begin{abstract}
Objectives The aim of the study was to identify the risk factors predisposing to morbidly adherent placenta and to study the different modes of management and the obstetric and neonatal outcome of these patients.

Methods This was a retrospective cum prospective observational study conducted in the Department of Obstetrics and Gynaecology in a tertiary care referral hospital in Mumbai from January 2012 to November 2014. Results The incidence of morbidly adherent placenta was 1.32 per 1000 pregnancies with patient profile comprising second gravida in the age group 26-28 years; $90 \%$ of the patients in this study had previous Caesarean section and co-existing placenta praevia was diagnosed in $63 \%$. Fiftythree per cent of the women delivered between 35 and 38 weeks and $40 \%$ had elective deliveries. Caesarean section was the mode of delivery in $90 \%$ of the patients.
\end{abstract}


Prophylactic balloon placement in the internal iliac artery followed by classical Caesarean section, uterine artery embolization and post-operative methotrexate was done in $27 \%$ which preserved the uterus and was associated the blood loss of 1000-2000 mL.

Conclusion Antenatal diagnosis of morbidly adherent placenta allows for multidisciplinary planning in an attempt to minimize potential maternal or neonatal morbidity and mortality.

Keywords Placenta accreta - Previous Caesarean section . Postpartum haemorrhage · Peri-partum hysterectomy . Internal iliac artery balloon catherisation . Utrine artery embolisation

\section{Introduction}

Obstetric haemorrhage is one of the leading causes of maternal deaths in developing nations especially in India. Abnormal placentation (accreta, increta and percreta) has emerged over uterine atony as the leading indication for peripartum hysterectomy. However, these placental abnormalities rarely get detected before delivery [1-3]. Once a rare occurrence, morbidly adherent placenta is now becoming an increasingly common complication of pregnancy, mainly due to the increasing rate of Caesarean delivery over the past 50 years [4]. It is the most frequent indication for peripartum hysterectomy [5-7]. It addition, the incidence of perinatal complications is also increased due to preterm birth and small for gestational age foetuses $[8,9]$.

In this study, an attempt has been made to enumerate possible measures to identify the predictors of abnormal placentation during early pregnancy in order to ensure favourable maternal and perinatal outcome.

\section{Materials and Methods}

This was a retrospective cum prospective observational study conducted in the Department of Obstetrics and Gynaecology in a tertiary care referral hospital in Mumbai between January 2012 and November 2014.

The study included all pregnant women, irrespective of parity status, with gestational age more than 26 weeks who had any type of morbidly adherent placenta diagnosed on USG colour Doppler/magnetic resonance imaging (MRI) or had been diagnosed intra-operatively with morbidly adherent placenta. All patients included had delivered in this institution.

For prospective cases, complete history and physical examination of the patient along with relevant investigations (ultrasound with colour doppler and MRI) for diagnosis of morbidly adherent placenta were documented. Hospital records were studied for the retrospective cases.

The parameters studied were the mode of presentation of the patient and longevity of the gestation, history of previous lower segment/classical Caesarean section or and other intrauterine operative procedure (dilatation and curettage, manual removal of placenta, myomectomy, etc.), mode of delivery of the current pregnancy, interventional end point (packing/prophylactic balloon placement in internal iliac artery/internal iliac artery ligation/uterine artery embolization/hysterectomy-classical/lower segment/ peri-partum), neonatal outcome and duration of hospital stay.

Each patient was followed up to 2 months post-partum with serial monitoring of serum beta HCG levels and doppler ultrasound for placental volume.

\section{Results}

During the study period, there were 22,653 deliveries, of which 30 patients had morbidly adherent placenta, giving an incidence on 1.32 per 1000 pregnancies. Being a tertiary care institute, $53 \%$ (16) patients were transferred from primary and secondary institutes. The maximum number of women $(11,36 \%)$ in the study belonged to the age group 26-28 years and $47 \%$ (14) of women were second gravida.

Forty-three per cent (13) had undergone both Caesarean section and emergency curettage. In total, $90 \%$ of the patients had undergone previous Caesarean section, of which $50 \%$ (15) had 1 previous Caesarean section, $30 \%$ (9) had previous 2 Caesarean sections and $10 \%$ (3) had previous 3 Caesarean sections. Amongst the $10 \%$ (3) who did not have previous lower segment Caesarean section, one patient was a primigravida with fibroid uterus, the second was a multigravida with previous full-term normal vaginal deliveries and the third was a multigravida with previous 2 abortions (with 2 previous emergency curettage for incomplete abortion) who were all diagnosed in the post-partum period (Table 1).

Co-existing placenta praevia was diagnosed in $63 \%$ (19) of the patients. Placenta accreta was found in $40 \%$ (12), placenta increta in $37 \%$ (11) and placenta percreta in $23 \%$ (7). Diagnosis of morbidly adherent placenta was made antenatally in $80 \%$ (24) patients, intra-operatively in $10 \%$ and post-natally in $10 \%$ due to post-partum haemorrhage. Diagnosis was made by ultrasound with colour doppler and confirmed with MRI. Mild anaemia $(\mathrm{Hb}$ $10-10.9 \mathrm{~g} / \mathrm{dL}$ ) at 32 weeks of gestation was found in $37 \%$ (11) and $23 \%$ (7) had severe anaemia $(\mathrm{Hb}<7 \mathrm{~g} / \mathrm{dL})$ (Figs. 1, 2). 
Table 1 Incidence, demographic profile and risk factors for morbidly adherent placenta

\begin{tabular}{|c|c|c|c|c|}
\hline Serial No. & Demographic variable & & No. of patients & Percentage \\
\hline \multirow[t]{3}{*}{1.} & \multirow[t]{3}{*}{ Morbidly adherent placenta } & Placenta accreta, increta, percreta & 30 & $1.32 / 1000$ pregnancies \\
\hline & & $23-25$ years & 3 & 10 \\
\hline & & $26-28$ years & 11 & 36 \\
\hline \multirow[t]{4}{*}{2.} & \multirow[t]{4}{*}{ Age } & 29-31 years & 8 & 27 \\
\hline & & $32-34$ years & 3 & 10 \\
\hline & & $35-38$ years & 5 & 7 \\
\hline & & Registered & 12 & 40 \\
\hline \multirow[t]{4}{*}{3.} & \multirow[t]{4}{*}{ Registration status } & Transferred & 16 & 53 \\
\hline & & Unregistered & 2 & 7 \\
\hline & & Nulligravida & 1 & 3 \\
\hline & & Gravida 1 & 4 & 13 \\
\hline \multirow[t]{5}{*}{4.} & \multirow[t]{5}{*}{ Gravidity } & Gravida 2 & 14 & 47 \\
\hline & & Gravida 3 & 5 & 17 \\
\hline & & Gravida 4 and above & 6 & 20 \\
\hline & & Previous caesarean section & 14 & 47 \\
\hline & & Previous curettage & 1 & 3 \\
\hline \multirow[t]{5}{*}{5.} & \multirow[t]{5}{*}{ Associated risk factors } & Both & 13 & 43 \\
\hline & & Neither & 2 & 7 \\
\hline & & Placenta praevia & 19 & 63 \\
\hline & & Accreta & 12 & 40 \\
\hline & & Increta & 11 & 37 \\
\hline \multirow[t]{2}{*}{6.} & \multirow[t]{2}{*}{ Type of placentation } & Percreta & 7 & 23 \\
\hline & & Antenatal & 24 & 80 \\
\hline \multirow[t]{3}{*}{7.} & \multirow[t]{3}{*}{ Time of diagnosis } & Intraoperative & 3 & 10 \\
\hline & & Post-natal & 3 & 10 \\
\hline & & No anaemia & 8 & 27 \\
\hline \multirow[t]{3}{*}{8.} & \multirow[t]{3}{*}{ Anaemia } & Mild anaemia (Hb 10-10.9 g\%) & 11 & 37 \\
\hline & & Moderate anaemia ( $\mathrm{Hb}$ 7-9.9 g\%) & 4 & 13 \\
\hline & & Severe anaemia $(\mathrm{Hb}<7 \mathrm{~g} \%)$ & 7 & 23 \\
\hline
\end{tabular}

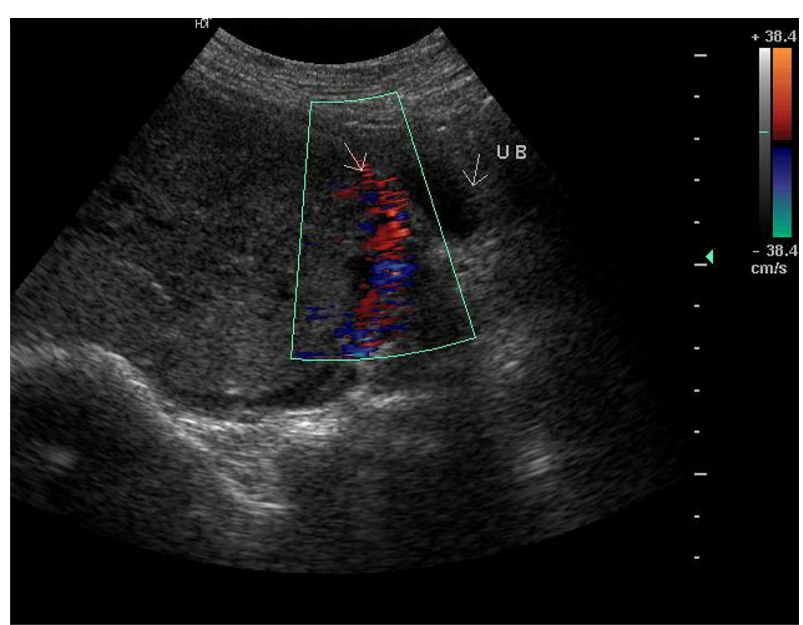

Fig. 1 Colour Doppler image of placenta praevia with placenta accreta

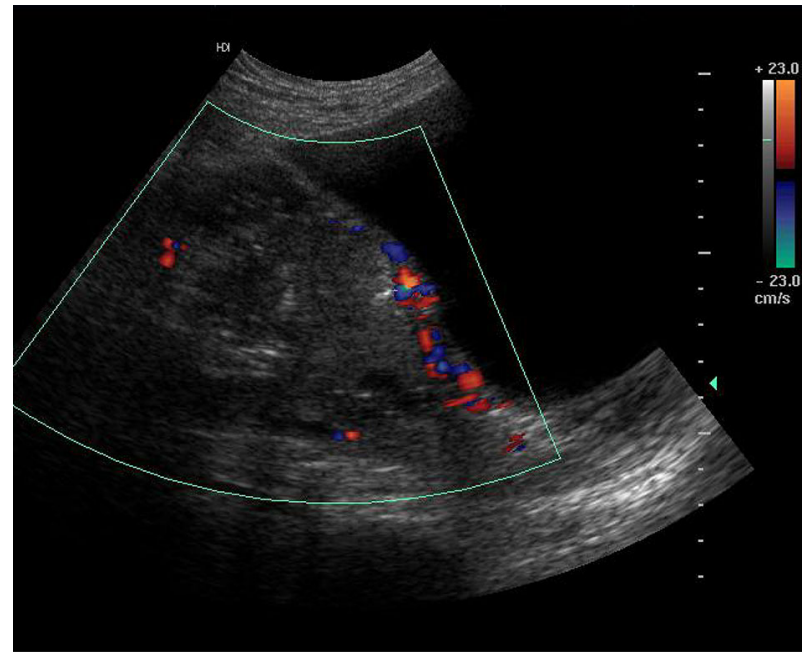

Fig. 2 Colour Doppler image of placenta increta 
Table 2 Gestational age at delivery

\begin{tabular}{llll}
\hline $\begin{array}{l}\text { Serial } \\
\text { No. }\end{array}$ & $\begin{array}{l}\text { Gestational } \\
\text { age (weeks) }\end{array}$ & $\begin{array}{l}\text { No. of } \\
\text { patients }\end{array}$ & $\begin{array}{l}\text { Percentage } \\
(\%)\end{array}$ \\
\hline 1. & $23-26$ & 1 & 3 \\
2. & $26-29$ & 3 & 10 \\
3. & $29-32$ & 3 & 10 \\
4. & $32-35$ & 3 & 10 \\
5. & $35-38$ & 16 & 53 \\
6. & $>38$ & 4 & 13 \\
\hline
\end{tabular}

Fifty-three per cent of the women delivered between 35 and 38 weeks. Forty per cent (12) of the patients had no complaints, and they had planned deliveries by a multidisciplinary team (an obstetrician, a blood bank team, anaesthetist, urologist, intensivist, an interventional radiologist and a neonatologist). Caesarean section was the most frequent mode of delivery $(90 \%, 20)$ with classical Caesarean section $(57 \%, 17)$ (in view of placenta praevia) being more frequent than lower segment Caesarean section $(33 \%, 10)$. The patients who had full-term normal vaginal deliveries $(7 \%, 2)$ as well as instrumental delivery (outlet forceps delivery) $(3 \%, 1)$ were diagnosed with morbidly adherent placenta in the post-partum period (Table 2).

The average intrapartum blood loss in patients with morbidly adherent placenta was $1500-2000 \mathrm{~mL}$ which was the case in $47 \%$ (14) of the patients studied. More than half of the patients $(64 \%, 18)$ received $1-4$ units of blood. Twenty-seven per cent of the patients (8) underwent prophylactic balloon placement in the internal iliac artery followed by classical Caesarean section and uterine artery embolization and methotrexate; this procedure was also associated with a blood loss of 1000-2000 mL. Lower segment Caesarean section with internal iliac artery ligation and finally followed by obstetric hysterectomy was associated with a blood loss of more than $2000 \mathrm{~mL}$ in all the three patients where it was adopted. Uterine artery embolization followed by obstetric hysterectomy was associated with a blood loss of more than $3500 \mathrm{~mL}$. Peripartum hysterectomy was done in $33 \%$ (10) (Tables 3, 4).

There were $20 \%$ (6) of the patients who had disseminated intravascular coagulation (DIC) and $13 \%$ (4) who required ICU admissions; this comprised five patients who were transferred from other hospitals in view of the high risk of adherent placenta and one registered patient who was diagnosed with placenta increta post-natally after a normal delivery and an attempt of manual removal of the placenta. Complications (Fig. 3) were more common in transferred patients as well as those who were operated on emergency basis. There was one mortality in the study.

The average hospital stay for a woman diagnosed with morbidly adherent placenta was 27 days. Those patients
Table 3 Treatment modality (balloon-prophylactic balloon placement in the internal iliac artery, IIL-internal iliac artery ligation, UAE - uterine artery embolization)

\begin{tabular}{|c|c|c|c|}
\hline $\begin{array}{l}\text { Serial } \\
\text { No. }\end{array}$ & Treatment modality & $\begin{array}{l}\text { No. of } \\
\text { patients }\end{array}$ & $\begin{array}{l}\text { Percentage } \\
(\%)\end{array}$ \\
\hline 1. & $\begin{array}{l}\text { Hysterectomy with other } \\
\text { procedure }\end{array}$ & $\begin{array}{l}9 \text { (IIL-3, UAE-1, } \\
\text { Balloon-5) }\end{array}$ & 30 \\
\hline 2. & $\begin{array}{l}\text { Hysterectomy without other } \\
\text { procedure }\end{array}$ & 2 & 7 \\
\hline 3. & $\begin{array}{l}\text { Other procedure without } \\
\text { hysterectomy }\end{array}$ & $\begin{array}{l}15 \text { (UAE-4, } \\
\text { Balloon-11) }\end{array}$ & 50 \\
\hline 4. & $\begin{array}{l}\text { No hysterectomy and no } \\
\text { other procedure }\end{array}$ & 4 (Methotrexate-4) & 13 \\
\hline
\end{tabular}

Table 4 Intrapartum blood loss

\begin{tabular}{llll}
\hline $\begin{array}{l}\text { Serial } \\
\text { No. }\end{array}$ & $\begin{array}{l}\text { Blood loss } \\
(\mathrm{mL})\end{array}$ & $\begin{array}{l}\text { No. of } \\
\text { patients }\end{array}$ & $\begin{array}{l}\text { Percentage } \\
(\%)\end{array}$ \\
\hline 1. & Less than 1999 & 19 & 63 \\
2. & $2000-2999$ & 7 & 23 \\
3. & $3000-3499$ & 2 & 7 \\
4. & More than 3500 & 2 & 7 \\
\hline
\end{tabular}

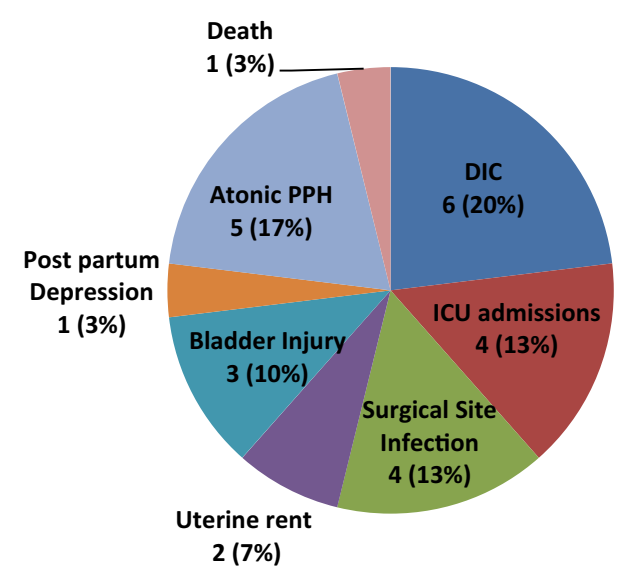

Fig. 3 Maternal outcome-morbidity and mortality

who received methotrexate and those who had surgical site infections had longer duration of hospital stay.

Seventy-nine per cent of the patients had live births, $14 \%$ had fresh stillbirths, and $7 \%$ had macerated stillbirths. Fifty per cent of the babies were preterm ( $<37$ weeks) and the maximum number of babies $(30 \%)$ had birth weight of 2300-2600 g. Twenty-seven per cent of the babies born required NICU admission for low birth weight, respiratory distress or neonatal jaundice. The neonatal death that occurred was due to respiratory distress in a preterm baby with low birth weight who was born with APGAR score of $3 / 10$ and $5 / 10$ at 1 and 5 min of life, respectively (Fig. 4). 


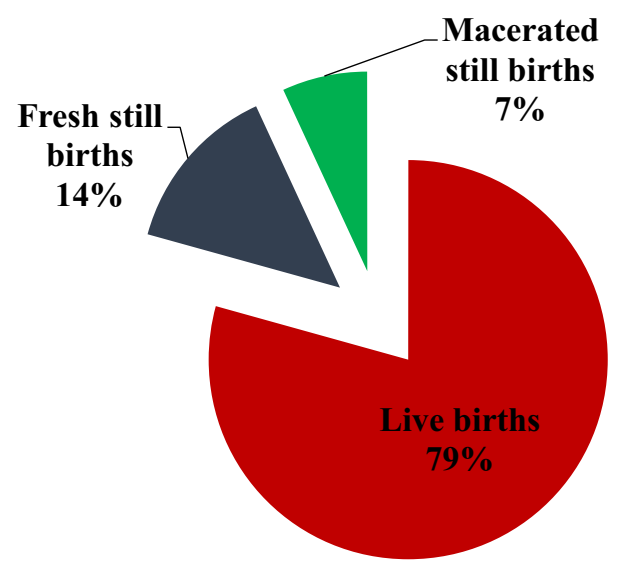

Fig. 4 Neonatal outcome

\section{Discussion}

Morbidly adherent placenta is one of the most devastating complications in pregnancy [10]. It is characterized by the attachment of placental villi directly to the myometrium, sometimes invading deeper into the uterine wall or surrounding organs. It could be placenta accreta (chorionic villi are in contact with the myometrium), placenta increta (chorionic villi invade the myometrium) or placenta percreta (chorionic villi penetrate the uterine serosa). The bladder is the most frequently involved extrauterine organ when there is a placenta percreta. Placenta percreta that invades the urinary bladder is associated with a substantial morbidity and mortality of up to $10 \%$ [11].

In this study, as well as studies by Aggarwal et al. [12] and Obajimi et al. [13], it is evident that morbidly adherent placenta usually occurs in subsequent pregnancies, explaining the older age group and higher gravidity of the patients. The most important risk factors are previous caesarean delivery, placenta praevia, multiparity and advanced maternal age [14]. Up to $88 \%$ of the women have concomitant placenta praevia $[15,16]$.

A majority of morbidly adherent placentae are diagnosed during the third stage of labour or during caesarean section which results in adverse consequences including exsanguinating haemorrhage [17]. Silent abnormal placentation was found in $21.2 \%$ of peripartum hysterectomy specimens in a study by Suwannarurk et al. [18]. The high rate of antenatal diagnosis of morbidly adherent placenta in this study could be due to the fact that the study was conducted in a tertiary care hospital receiving a large percentage of transferred patients (from peripheral health centres) where diagnostic facilities such as ultrasound with colour Doppler as well as MRI are available during both routine and emergency hours.
Regardless of the management option made, prevention of complications ideally requires a multidisciplinary team approach. Early planning of arrangements for antepartum and intrapartum management is preferable to late planning, when emergency situations are more likely to occur [19].

Given the best-available evidence, optimal time for delivery is believed to be between 34 and 35 weeks in most cases $[15,20]$. The recommended management of suspected morbidly adherent placenta is planned preterm Caesarean section with the placenta left in situ because attempts at removal of the placenta are associated with significant haemorrhagic morbidity [15]. A classical uterine incision, often transfundal, may be necessary to avoid the placenta, especially in cases of low lying placenta, and to allow delivery of the infant.

The reported maternal mortality for morbidly adherent placenta ranges from 7 to $10 \%$ worldwide [21]. Maternal morbidity had been reported to occur in up to $60 \%$ and mortality in up to $7 \%$ of women with morbidly adherent placenta $[8,9]$. Considering this risk of substantial morbidity (including coagulopathy, severe haemorrhage, infection, sepsis, ureteral injury, need for blood transfusion/hysterectomy) and mortality, uterus-preserving treatment may have a role in carefully selected patients who desire future fertility [22]. Several adjuvant techniques have been proposed alongside surgery. These include methotrexate treatment and/or placement of preoperative internal iliac artery balloon catheters for occlusion and/or arterial embolization to reduce intraoperative blood loss and transfusion requirements [23]. Although the sufficient literature on the efficacy of methotrexate is still lacking, Dasari et al. [24] reported the successful treatment with methotrexate of a primiparous patient who was diagnosed in the post-partum period and had no other co-morbidities. When conservative management is successful, it results in gradual resorption of the placenta or delayed delivery of the placenta [25].

\section{Conclusion}

Antenatal diagnosis of morbidly adherent placenta through imaging (ultrasound colour Doppler and MRI) allows for multidisciplinary planning in an attempt to minimize potential maternal or neonatal morbidity and mortality. Interventional radiological procedures help in preserving the uterus and hence the future fertility career of the patient. Randomized controlled trials and large cohort studies for the diagnosis and management of morbidly adherent placenta are lacking [26]. Although the gap between the developed and developing nations with regard 
to maternal mortality and morbidity may have narrowed, but still a lot of dedicated work is required to bridge these differences.

Acknowledgments There was no funding involved in this study.

\section{Compliance with Ethical Standards}

Conflict of interest All authors declare that they have no conflict of interest.

Ethical Approval All procedures performed in studies involving human participants were in accordance with the ethical standards of the institutional and/or national research committee and with the 1964 Helsinki Declaration and its later amendments or comparable ethical standards.

Informed Consent Informed consent was obtained from all individual participants included in the study.

\section{References}

1. Bajwa SK, Singh ABS. Contemporary issues in the management of abnormal placentation during pregnancy in developing nations: an Indian perspective. Int J Crit Illn Inj Sci. 2013;3(3):183-9.

2. Bauer ST, Bonanno C. Abnormal placentation. Semin Perinatol. 2009;33(2):88-96.

3. Yi KW, Oh M-J, Seo T-S, et al. Prophylactic hypogastric artery ballooning in a patient with complete placenta previa and increta. J Korean Med Sci. 2010;25(4):651-5.

4. Hamilton BE, Martin JA, Ventura SJ, et al. Births: preliminary data for 2004. Natl Vital Stat Rep. 2005;54(8):1-17.

5. Jagielska I, Kazdepka-Ziemińska A, Tyloch M, et al. Clinical study of perinatal hysterectomy between 2000-2011 in the clinic of obstetrics, gynecological diseases and oncological gynecology in Bydgoszcz. Ginekol Pol. 2014;85(3):192-6.

6. Dandolu V, Graul AB, Lyons AMD. Obstetrical hysterectomy, cesarean delivery and abnormal placentation. J Matern Fetal Med. 2012;25(1):74-7.

7. Roethlisberger M, Womastek I, Posch M, et al. Early postpartum hysterectomy: incidence and risk factors. Acta Obs Gynecol Scand. 2010;89(8):1040-4.

8. Eller AG, Porter TF, Soisson P, et al. Optimal management strategies for placenta accreta. BJOG. 2009;116(5):648-54.

9. Sumigama S, Itakura A, Ota $\mathrm{T}$, et al. Placenta previa increta/ percreta in Japan: a retrospective study of ultrasound findings, management and clinical course. J Obstet Gynaecol Res. 2007;33(5):606-11.
10. Tikkanen M, Paavonen J, Loukovaara MSV. Antenatal diagnosis of placenta accreta leads to reduced blood loss. Acta Obs Gynecol Scand. 2011;90(10):1140-6.

11. Bennett MJSR. "Conservative" management of placenta praevia percreta: report of two cases and discussion of current management options. Aust N Z J Obs Gynaecol. 2003;43:249-51.

12. Aggarwal R, Suneja A, Vaid NB, et al. Morbidly adherent placenta: a critical review. J Obstet Gynaecol India. 2012;62(1):57-61. doi:10.1007/s13224-012-0149-5.

13. Obajimi GO, Roberts AO, Aimakhu CO, et al. An appraisal of retained placentae in ibadan: a five year review. Ann Ibadan Postgrad Med. 2009;7(1):21-5.

14. Wu S, Kocherginsky MHJ. Abnormal placentation: twenty-year analysis. Am J Obs Gynecol. 2005;192(5):1458-61.

15. Garmi G, Salim R. Epidemiology, etiology, diagnosis, and management of placenta accreta. Obstet Gynecol Int. 2012;2012:873929.

16. Armstrong CA, Harding S, Matthews T, et al. Is placenta accreta catching up with us? Aust $\mathrm{N}$ Z J Obstet Gynaecol. 2004;44(3):210-3.

17. Herath R, Wijesinghe P. Management of morbidly adherent placenta. Sri Lanka J Obstet Gynaecol. 2012;33(2):39-44.

18. Suwannarurk K, Thaweekul Y, Mairaing K, et al. Silent abnormal placentation linkage to peripartum hysterectomy: Thammasat University Hospital 6-year study. J Med Assoc Thai. 2014;97(5):473-7.

19. El-Messidi A, Mallozzi AOL. A multidisciplinary checklist for management of suspected placenta accreta. J Obs Gynaecol Can. 2012;34(4):320-4.

20. Belfort M. Indicated preterm birth for placenta accreta. Semin Perinatol. 2011;35(5):252-6.

21. Chandraharan E, Rao S, Belli AMAS. The Triple-P procedure as a conservative surgical alternative to peripartum hysterectomy forplacenta percreta. Int J Gynaecol Obs. 2012;117(2):191-4.

22. Allahdin S, Voigt S, Htwe TT. Management of placenta praevia and accreta. J Obstet Gynaecol. 2011;31(1):1-6.

23. Tan $\mathrm{CH}$, Tay KH, Sheah K, et al. Perioperative endovascular internal iliac artery occlusion balloon placement in management of placenta accreta. AJR Am J Roentgenol. 2007;189(5):1158-63.

24. Dasari P, Venkatesan B, Thyagarajan C, et al. Expectant and medical management of placenta increta in a primiparous woman presenting with postpartum haemorrhage: the role of imaging. J Radiol Case Rep. 2010;4(5):32-40.

25. Breathnach F, Tuite DJ, McEniff N, et al. Uterine artery embolisation as an interval adjunct to conservative management of placenta praevia increta. J Obstet Gynaecol. 2007;27(2):195.

26. Hayes E, Ayida G, Crocker A. The morbidly adherent placenta: diagnosis and management options. Curr Opin Obstet Gynecol. 2011;23(6):448-53. 